\title{
MORFOLOGIA DOS FRUTOS, SEMENTES E PLÂNTULAS DE Platonia insignis MART. (CLUSIACEAE). II. MORFO-ANATOMIA DOS FRUTOS E SEMENTES MADUROS ${ }^{1}$.
}

\author{
Káthia Socorro Mathias MOURÃO ${ }^{2}$, Celia Massa BELTRATI ${ }^{3}$
}

\begin{abstract}
RESUMO - O fruto de Platonia insignis é uma baga uniloculada cuja forma varia de oblata a oblonga. $\mathrm{O}$ exocarpo é unisseriado; o mesocarpo é parenquimático, contendo numerosos dutos secretores e feixes vasculares ramificados; o endocarpo constitui a camada pulposa que envolve as sementes no fruto maduro, quando se destaca do restante do pericarpo. As camadas celulares mais internas do endocarpo são radialmente alongadas e permanecem firmemente aderidas às camadas mais externas da testa, por meio de interdigitações. As sementes são anátropas e se tornam unitegumentadas e exalbuminosas. A testa é multisseriada e apresenta numerosos feixes vasculares que partem do feixe rafeal único como ramos pós-calazais; o tégmen encontra-se colapsado, sendo distintos apenas alguns braquisclereídes dispersos. O embrião, do tipo conferruminado, consta de um espesso eixo hipocótilo-radícula, rico em reservas lipídicas, em cujo meristema fundamental estão presentes abundantes dutos secretores.
\end{abstract}

Palavras-chave: Platonia insignis Mart.; fruto e semente maduros.

Fruit, Seed and Seedling Morphology of Platonia insignis Mart. (Clasiaceae). II MorphoAnatomy of Mature Fruits and Seeds.

SUMMARY - The fruit of Platonia insignis is an unilocular berry; oblate to oblong in shape. The exocarp is uniseriate; the mesocarp is parenchymatic, with branched secretory ducts and vascular bundles. At maturation, the endocarp constitutes the pulpy layer which involves the seed, when it is released from the rest of the pericarp; the inner endocarp cell layers are radially elongated and remain firmly attached to the testal outer layers. The mature seeds are anatropous, becoming unitegmic and exalbuminous; the testa is multiseriate and shows a single rapheal vascular bundle with many postchalazal branches; the tegmen is almost completly crushed, showing only some scattered brachisclereids. The conferruminate embryo is constituted by a thick radiclehypocotyl axis which is rich in lipids. Secretory ducts occur in the fundamental cortical meristem of the embrionary axis.

Key words: Platonia insignis Mart; riped fruit and seed.

\section{INTRODUÇÃo}

$\mathrm{Na}$ família Clusiaceae, aos caracteres vegetativos e florais têm sido atribuido valor diagnóstico, a nível genérico e específico, enquanto que as características dos frutos e das sementes têm sido utilizadas na delimitação de subfamílias e tribos.

Revendo a literatura, observou- se que são poucos os trabalhos que tratam dos frutos e sementes de Platonia insignis. Foram encontradas somente descrições morfológicas gerais (ENGLER, 1888; ROOSMALEN, 1985a) e, principalmente, análises químicas destes órgãos (PESCE, 1934; PAULA, 1945; PECHNIK \& CHAVES, 1945; CAMPOS et al., 1951; PECHNIK et al., 1962; ALVES \&

I Parte da Dissertação de Mestrado da primeira autora. Projeto subvencionado pela CAPES e pela FAPEMA.

2 Depto de Biolgia, UEM, Av. Colombo, 5790, Maringá - PR, CEP:87020-900

3 Depto. de Botânica, IB / UNESP - Caixa Postal 199, Rio Claro, São Paulo, CEP: 13506-900 
JENNINGS, 1979; NAZARÉ \& MELO, 1981).

MOURÃO \& BELTRATI (1995)

descreveram a ontogênese dos frutos e das sementes em $P$, insignis esclarecendo definitivamente a origem endocárpica da polpa comestível que envolve as sementes. Dando continuidade a este estudo, o presente trabalho teve por objetivo fornecer dados morfológicos e anatômicos a respeito dos frutos e sementes maduros desta espécie, como subsídios para futuros estudos taxonômicos e ecológicos.

\section{MATERIAL E MÉTODOS}

Frutos e sementes maduros de $P$. insignis foram coletados de 20 indivíduos localizados no Parque Estadual do Itapiracó, área sob a responsabilidade da Secretaria de Meio Ambiente e Turismo do Estado do Maranhão (SEMATUR), situada a $2^{\circ} 32^{\circ}$ de latitude sul e $44^{\circ} 17^{\circ}$ de longitude oeste, no município de São Luís (MA).

Parte do material coletado foi herborizado, devidamente identificado $\mathrm{e}$ depositado como documento taxonômico no Herbário do Departamento de Biologia da UFMA - São Luís sob os números de registro 2442 a 2452 e no Herbarium Rioclarense (HRCB), do Instituto de Biociências, UNESP - Rio Claro sob os números de registro 10866 a 10875,11121 a 11126.

Os estudos morfológicos e anatômicos foram realizados conforme metodologia descrita por MOURÃO \& BELTRATI (1995).

As características morfológicas dos frutos e sementes foram descritas e ilustradas, a partir de 200 unidades de material fresco.

As amostras foram provenientes de dois grupos de dez árvores, de início selecionadas de acordo com a forma dos frutos que apresentavam-se redondos ou compridos.

Os frutos foram considerados "compridos", quando o seu comprimento foi maior que o diâmetro, e "redondos" quando o comprimento foi menor ou igual ao diâmetro.

Para determinação das dimensões (comprimento e diâmetro) dos frutos e sementes, utilizou-se um paquímetro, e o peso fresco foi obtido com balança de precisão. Determinou-se também o número de sementes e o número de formações pulposas por fruto. Esses dados foram colocados em histogramas de frequência.

Para cada uma das variáveis obtidas, calculou-se a média aritimética, o desvio-padrão, o erro padrão da média e a amplitude de variação.

A terminologia utilizada na descrição dos caracteres morfoanatômicos dos frutos e sementes foi baseada nos trabalhos de RADFORD et al. (1974), CORNER (1976), ROTH (1977) e FONT QUER (1985).

\section{RESULTADOS}

O fruto maduro é do tipo baga, possuindo pericarpo bastante espesso e carnoso. Sua forma varia de oblata a oblonga (Figs. 1 e 2), passando por uma série de tipos intermediários. Em uma mesma árvore, a forma dos frutos mostrou-se uniforme.

A coloração externa do fruto 
maduro varia do verde-amarelado ao marrom-avermelhado.

O fruto é uniloculado (Figs. 3 a 5,22 e 23 ), sendo observada, nas porções correspondentes a cada lóculo do ovário, a presença de uma a três sementes superpostas (Fig. 6). Nos demais lóculos observam-se somente óvulos abortados, envolvidos pelo endocarpo pulposo (Figs. 3, 4, 6 e 23).

Os valores dos dados morfométricos dos frutos de Platonia. insignis, bem como da análise estatística encontram-se listados na Tabela 1 e podem ser observados através das figuras 7 a 9 .

No fruto maduro, o exocarpo é unisseriado, mostrando reentrâncias acentuadas (Fig. 13).

O mesocarpo é de natureza parenquimática, apresentando dutos secretores numerosos e anatomosados (Figs. 14, 15, 22 e 23), cujo conteúdo deu reação positiva para lipídios e para compostos fenólicos.

$O$ endocarpo encontra-se totalmente aderido à semente $\mathrm{e}$ separado do restante do pericarpo. A separação ocorre entre as camadas celulares mais externas do endocarpo (Fig. 14), principalmente por dissolução das lamelas médias, e também por destruição de algumas células (Figs. 15 e 16). A região de separação estendese por entre os septos, delimitando as sementes e os óvulos abortados (Fig. 23).

Mais internamente o endocarpo é composto por células bastante alongadas, de paredes finas, e ricas em açucares (Figs, 14, 15, 17 a 20), constituindo a camada pulposa propriamente dita. Imersos neste tecido encontram-se alguns feixes vasculares finos (Figs. $14 \mathrm{e} \mathrm{15).}$

As sementes são anátropas, de forma elipsóide, podendo ser mais ou menos angulosas, dependendo do número de sementes por fruto (Figs. 6e 24). Nos casos em que se desenvolvem duas ou três sementes em um só lóculo, estas têm forma aproximadamente tetraédrica e são de tamanho menor (Fig. 6). Encontram-se inseridas na columela central, ligadas por um funículo curto e delgado (Fig. 5).

Após a retirada do endocarpo pulposo, pode-se observar que o envoltório da semente é de cor marrom, percorrido por feixes vasculares ramificados, bem evidentes por sua coloração mais clara. $\mathrm{O}$ hiloé arredondado, de coloração escura, havendo uma pequena região mais

Tabela 1. $P$. insignis. Fruto: dimensões, peso freco, número de sementes e número de formações pulposas do endocarpo. $(\mathrm{N}=200)$.

\begin{tabular}{lcccc}
\hline \multicolumn{1}{c}{ VARIÁVEIS } & MÉDIA & $\begin{array}{c}\text { DESVIO } \\
\text { PADRÃO }\end{array}$ & $\begin{array}{c}\text { ERRO } \\
\text { PADRÃO }\end{array}$ & $\begin{array}{c}\text { AMPLITUDE } \\
\text { DE VARIAÇÃO }\end{array}$ \\
\hline Comprimento $(\mathrm{cm})$ & 8.0 & 1.3 & 0.1 & $5.1-13.0$ \\
Diâmetro $(\mathrm{cm})$ & 7.6 & 0.9 & 0.0 & $4.9-9.9$ \\
Peso fresco $(\mathrm{g})$ & 257.9 & 88.0 & 6.2 & $64.4-532.2$ \\
№ de sementes & 2.3 & 0.9 & 0.0 & $1.0-6.0$ \\
№ de formações pulposas & 2.6 & 1.0 & 0.1 & $0.0-50$ \\
\hline
\end{tabular}




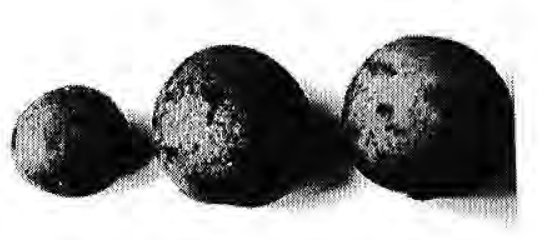

1
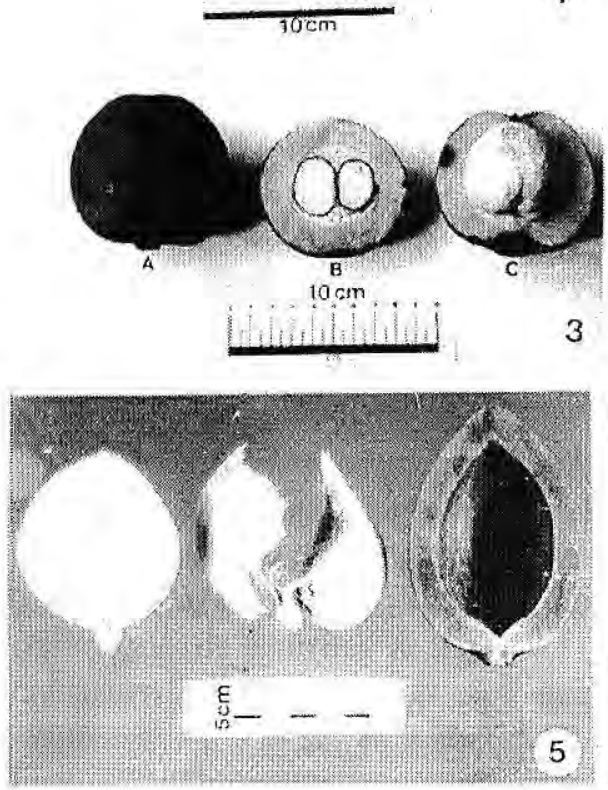
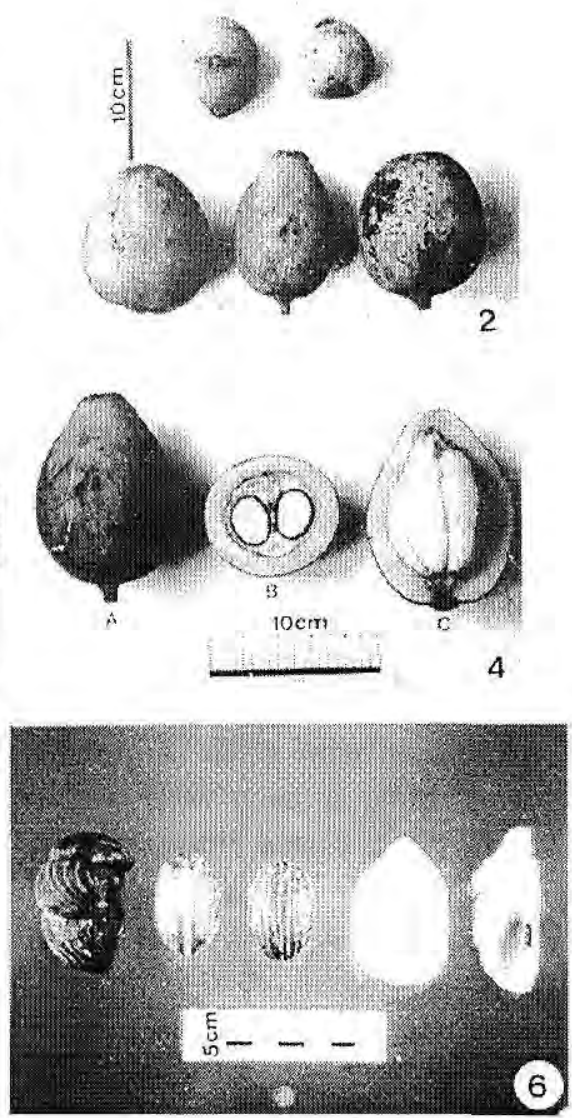

Figuras 1 a 6. 1-2; Frutos maduros esféricos ealongados. tespectivamente, mostrando variação de tamanho; 3-4: l'ruto maduro esférico e alongado, respectivamente, intacto $(A)$, cortado transversalmete (B) e longitudinalmente (C): 5 (da direita para a esquerda): Truto maduro cortado longitudinalmente, sem as sementes e sem as formaçoes do endocarpo: sementes ainda ligadas ao cixo do fruto; e conjunto formado pelas sementes e pelas formaçóes do endocarpo: 6 (da direita para a esquerda); lormação do endocarpo: semente com o endocarpo; sementes sem o endocarpo em vista anti-rafeal e rafeal; conjunto de três sementes superpostas. 
MUMERO DE FFUTOS

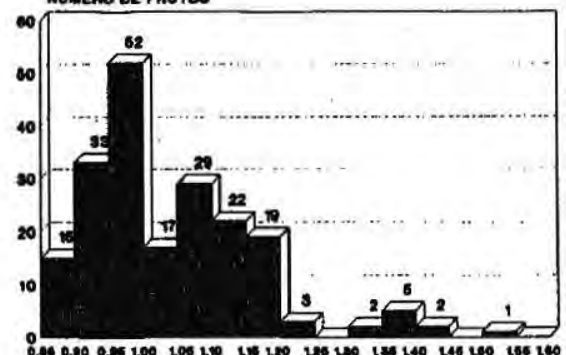

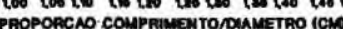

7

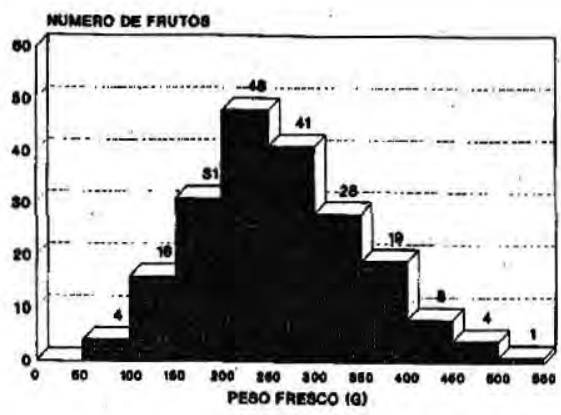

8

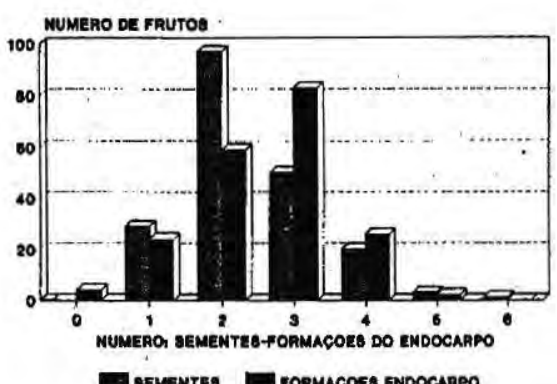

9

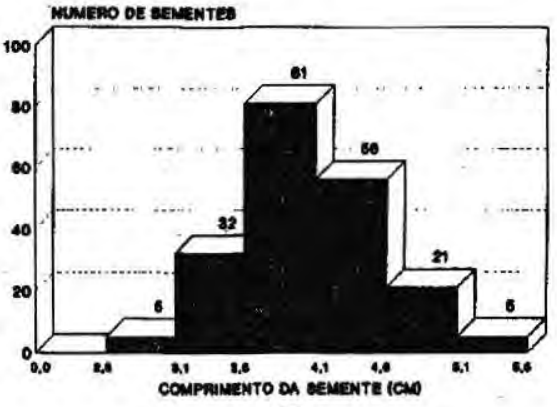

10



11



12

Figuras 7 a 12. 7-9: Fruto - Histogramas de frequência: 7: Proporção comprimento/diâmetro (cm); 8: peso fresco $(\mathrm{g})$; 9: número de sementes e de formações do endocarpo por fruto; 10 a 12. Semente - Histogramas de frequência: 10 . Comprimento $(\mathrm{cm}) ; 11$ : Diâmetro $(\mathrm{cm}) ; 12$ : Peso fresco (g). 



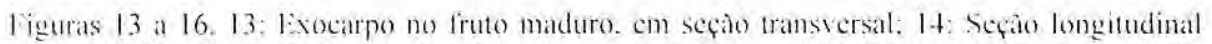
(lo pericarpo $\mathrm{cm}$ um fruto juvem $(3.0 \mathrm{~cm}$ de comprumento). evidenciando a reglào de separação na parte externa do endocarpo: 15: Seçâo transversal do pericarpo mostrando o inicio da separaçăo do endocarpo: 16: Detalhe da regiào indicada na ligura 15. (ce = célula epidérmica: $\mathrm{cl}=$ célula alongada do endocarpo: $\mathrm{ls}=$ duto secretor; ee $=$ endocarpo; $f \mathrm{v}=$ feixe vascular: $m p=$ mesocarpo. As setas indicam a região de separação) 

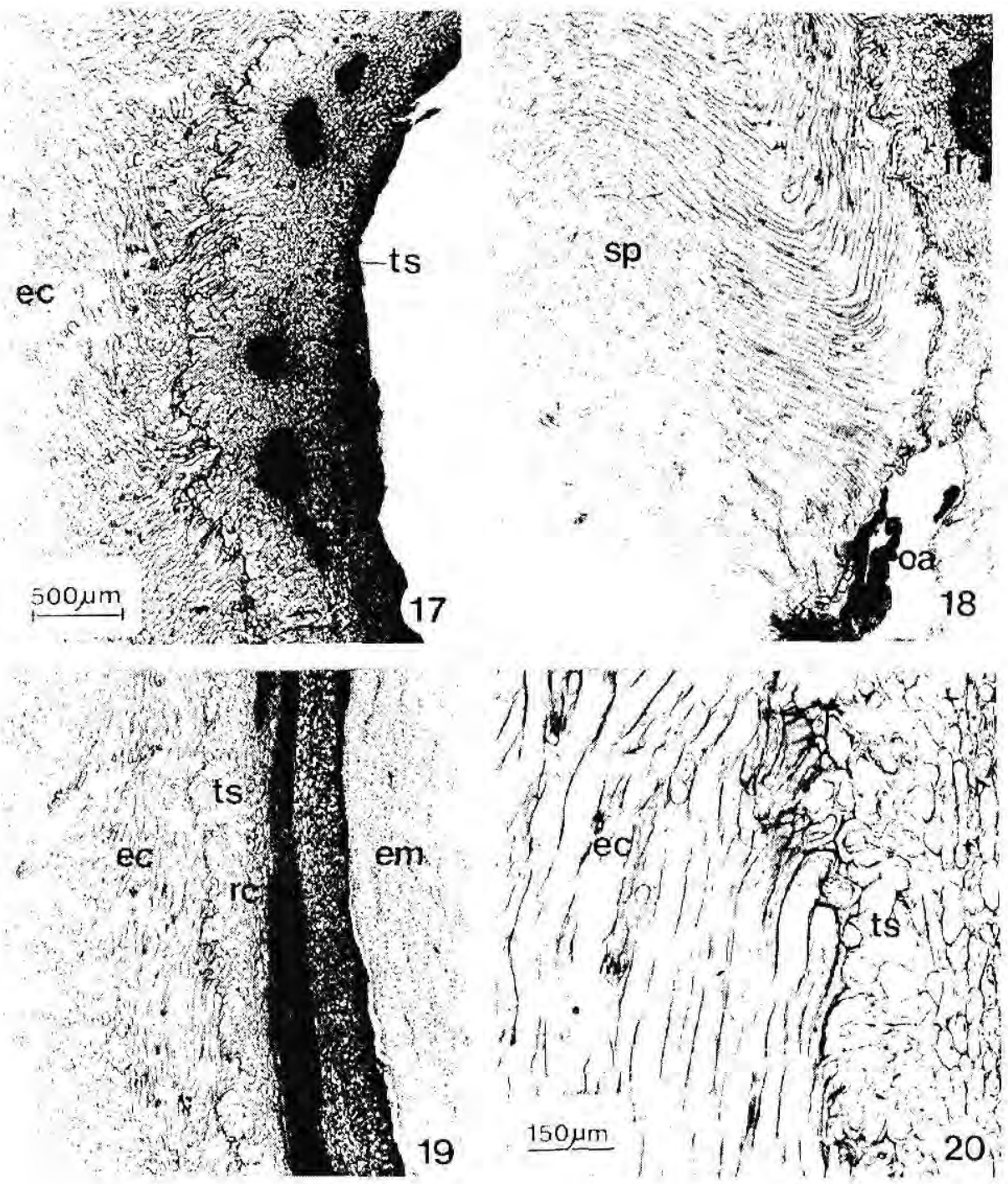

Figuras 17 a 20 . Regiâo de união da testa com o endocarpo no fruto quase maduro. 17: I:m seçào transversal: 18: l:m seçào transversal na regiào do septo; 19: lim seção longitudinal; 20): Detalhe da seçào longitudinal (ec $=$ endocarpo; $\mathrm{em}=\mathbf{e m b r i a n o} ; \mathbf{f r}=$ feixe vascular rafeal; $0 a=$ ovvulo abortado; $r c=$ ramificação pós-calazal do feixe rafeal; $s p=s e p t o ; t s$ = testa) 



Figuras 21 a 29. 21-23: Fruto maduro; 21: Aspecto geral extemo; 22 e 23: Diagramas das seções longitudinal e transversal, respectivamente; 24 a 29: Semente madura e embrião; 24: Aspecto geral de uma semente oblongo-angulosa, mostrando a vascularização da testa; 25 e 26: Aspecto geral do embrião em vista ventral e dorsal, respectivamente; 27: Diagrama da seção longitudinal mediana do embrião; 28: Detalhe da região dos cotilédones; 29: Diagrama da seção transversal mediana do embrião. (ca = região calazal; cp = cilindro procambial; $\mathrm{ct}=$ cotilédone; $\mathrm{ds}=$ duto secretor; $\mathrm{ec}=$ endocarpo; $\mathrm{eh}=$ eixo hipocótilo radicula; $\mathrm{fv}=$ feixe vascular; $\mathrm{hl}=\mathrm{hilo} ; \mathrm{lo}=$ lóculo; $\mathrm{ma}=$ maristema apical caulinar; $\mathrm{mc}=$ meristema fundamental cortical; $\mathbf{m i}=$ micrópila; $\mathbf{m m}=$ meristema fundamental medular; $\mathbf{m p}$ $=$ mesocarpo; $\mathrm{mr}=$ meristema apical radicular; $\mathrm{pt}=$ protoderme; $\mathrm{ra}=$ rafe; $\mathrm{rc}=$ ramificação póscalazal do feixe rafeal; $\mathrm{rd}=$ radícula; se $=$ semente). 

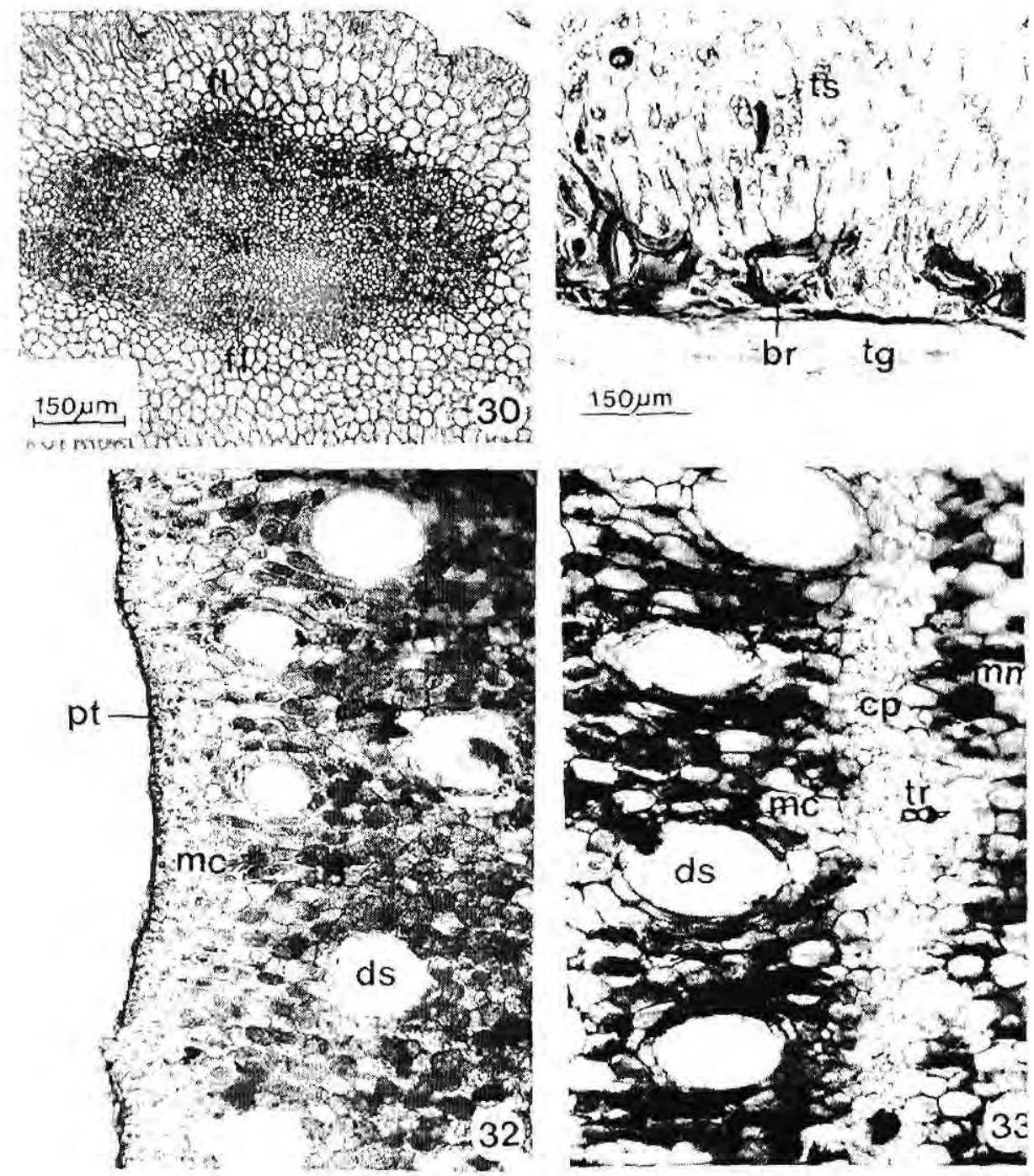

Figuras 30 a 33.30 < 31 : Semente quase madura em secão transversal. 301: Detallhe do licixe vascular raleal: 31 : Detalhe da parte interna da testa e do tégmen mostrando os braquiselerédes: 32 e 33: Detalhe do embrião em seção transversal 32: Proloderme e camadas mais externas do meristema fundamental cortical; 33: Parte do cilindro procambial, camadas mais internas do meristema fundamental cortical e cambalas mais externas do meristema femdamental, (br $=$ braquiscleréde $\mathrm{cp}=$ cilindro procambial $\mathrm{l} \mathrm{s}=$ duto secretor; $\mathrm{fl}=$ floema; $m \mathrm{c}=$ meristema cortical; $\mathrm{mm}=$ meristema fundamental medular; $\mathrm{pt}=$ protolerme; $\mathrm{tg}=$ tégmen; $t r=$ traqucide; $t s=$ testa; $x i=x i l e m a B)$ 
clara no centro, correspondente ao ponto de entrada do feixe vascular. A micrópila situa-se próximo do hilo sobre uma pequena protuberância triangular (Figs. 6 e 24).

O robusto feixe vascular, que percorre a rafe, ao atingir a calaza emite ramificações constituidas por feixes concêntricos anficrivais (Fig. 30) que divergem imersos no mesofilo da testa, e posteriormente convergem, nas proximidades da região micropilar (Figs 6 e 24).

O embrião (Figs. 25 a 29), na semente madura, consta unicamente de um longo e espesso eixo hipocótilo-radícula, sendo os cotilédones vestigiais. Por seu tamanho extremamente reduzido, são dificilmente distintos, aparecendo externamente, apenas uma pequena fenda lateral localizada próximo à extremidade superior do eixo, no lado oposto à micrópila (Figs. 25 e 26). Entre os diminutos cotilédones localiza-se o meristema apical do caule (Figs 27 e 28).

A semente madura é desprovida de endosperma, estando todo o material de reserva armazenado no volumoso eixo hipocótilo-radícula.

Os valores dos dados morfométricos das sementes, bem como da análise estatística encontram-se listadas na Tabela 2 e podem ser observados através das figuras 10 a 12 .
$\mathrm{Na}$ semente madura, a testa mostra uma região externa representada pela epiderme e pelas primeiras camadas subepidérmicas que são ricas em óleo e que formam interdigitações com as células do endocarpo (Fig. 20), e uma região interna com células amassadas, de paredes espessadas, onde se encontram os feixes vasculares bastante comprimidos. O tégmen encontra-se totalmente amassado, restando visíveis apenas os braquisclereídes, dispersos entre a testa e o embrião (Fig. 31).

No eixo embrionário a protoderme é constituída por células cubóides de paredes delgadas, celulósicas, cobertas por fina cutícula (Fig. 32). O meristema fundamental, que aparece nas regiões cortical e medular, é composto por células arredondadas, de paredes finas, de natureza celulósica, e muito ricas em gotículas de material lipídico. Entre as regiões cortical e medular existe um cilindro procambial, onde se observam alguns elementos traqueais em diferenciação (Figs. 27, 29, 32 e 33).

O cilindro procambial percorre todo o eixo e se encurva em direção aos minúsculos cotilédones. A porção cortical é rica em dutos secretores anastomosados, que percorrem longitudinalmente o eixo encurvandose também em direção aos diminutos

Tabela 2. Dimensões e peso de sementes frescas de $P$. insignis. $(\mathrm{N}=200)$.

\begin{tabular}{lcccc}
\hline \multicolumn{1}{c}{ VARIÁVEIS } & MÉDIA & $\begin{array}{c}\text { DESVIO } \\
\text { PADRÃO }\end{array}$ & $\begin{array}{c}\text { ERRO } \\
\text { PADRÃO }\end{array}$ & $\begin{array}{c}\text { AMPLITUDE } \\
\text { DE VARIAÇÃO }\end{array}$ \\
\hline Comprimento $(\mathrm{cm})$ & 4.0 & 0.5 & 0.0 & $2.7-5.3$ \\
Diâmetro $(\mathrm{cm})$ & 2.8 & 0.3 & 0.0 & $2.0-37$ \\
Peso fresco $(\mathrm{g})$ & 15.1 & 4.8 & 0.3 & $6.3-29.7$ \\
\hline
\end{tabular}


cotilédones (Figs. 27 e 29). Os dutos secretores podem ser observados em diversos estádios de diferenciação, sendo que os dutos menos diferenciados aparecem tanto nas proximidades da protoderme como próximo do cilindro procambial (Figs. 29, 32 e 33). Não ocorrem, porém, na região medular (Figs. 27 e 29).

Esses dutos secretam uma substância complexa, tendo seu conteúdo dado reação positiva para lipídios e para compostos fenólicos.

\section{DISCUSSÃO E CONCLUSÕES}

Os frutos de Platonia insignis enquadram-se no tipo baga, descrito por diversos autores, tais como: ENGLER (1888), PIO CORRÊA (1926), MANIERI \& LOUREIRO (1964), CAVALCANTE (1976), BERG (1982), ROOSMALEN (1985a). Com relação às dimensões e peso dos frutos e sementes frescos, estes autores não realizaram estudos pormenorizados, tendo apresentado somente descrições gerais.

Pelo presente estudo, observouse grande amplitude de variação nos dados morfométricos dos frutos e sementes. É importante ressaltar porém, a uniformidade nas dimensões, na forma e no peso dos frutos frescos provenientes de um mesmo indivíduo, o que demonstra serem esses caracteres bem fixados geneticamente.

CALZAVARA (1970) considerou que tomando por base a forma do fruto e a presença ou não de sementes, seria possível distinguir três variedades dentro de $P$. insignis: "o bacuri comprido" cujos frutos são piriformes ou ovalados, "o bacuri redondo", com frutos que apresentam forma arredondada, e o "bacuri sem semente", variedade encontrada na Illa de Marajó, de frutos redondos e se caracterizando por não produzir sementes. Este autor, entretanto, faz essas afirmações sem haver realizado estudos morfométricos.

No presente trabalho, o critério inicialmente utilizado para a separação das amostras de frutos, em "redondos" ou "compridos", foi baseado nas considerações de CALZAVARA (1970). Porém, após a análise dos dados morfométricos, verificou-se não ser adequado esse críterio, uma vez que dentro de uma população, a forma do fruto é um carater de variação contínua. O mesmo ocorre com as dimensões e peso das sementes frescas, provenientes dos frutos de qualquer das formas. Assim sendo, as amostras passaram a ser analisadas em conjunto.

Pelo presente estudo, portanto, concluiu-se não ser possível o estabelecimento de variedades de $P$. insignis com base apenas na forma do fruto, como propôs CALZAVARA (1970).

Embora de valor taxonômico questionável, os dados morfométricos de frutos e sementes têm indiscutível valor ecológico, auxiliando no estudo da variabilidade da espécie, bem como do tipo de dispersão e dos agentes dispersores (OLIVEIRA, 1991).

As grandes dimensões dos frutos de $P$. insignis permitem a utilização de agentes dispersores de grande porte, como é o caso do Ateles paniscus paniscus Linnaeus ("Macaco aranha preto") que inclui os frutos dessa espécie em sua dieta alimentar 
(ROOSMALEN, 1985b).

Pela análise química do mesocarpo de Platonia insignis realizada por PAULA (1945), foi constatada a ocorrência de uma resina, obtendo também, nessa região, reação positiva para tanino. No presente trabalho, tanto no mesocarpo quanto no meristema fundamental cortical do embrião, o material secretado nos dutos deu reação positiva para lipídios e para compostos fenólicos. Segundo METCALFE \& CHALK (1983), os testes aplicados por diferentes pesquisadores para o mesmo material podem levar a conclusões diversas, uma vez que o material secretado raramente é constituido por substâncias puras.

A constituição química da polpa de $P$. insignis foi analisada por CAMPOS et al. (1951). Estes autores encontraram $13,3 \%$ de carboidratos totais, sendo estes os maiores componentes depois da água $(70 \%)$. No presente trabalho obteve-se resultado positivo para açucares, nos dois testes utilizados.

Com relação à semente madura, várias características gerais citadas por CORNER (1976) para as sementes de espécies de Clusiaceae são encontradas também em $P$. insignis, tais como: sementes grandes; exalbuminosas; com testa e tégmen multiplicativos (tribo Garcinieae); exotégmen com células de paredes espessas e lignificadas, intercrescidas com a endotesta (tribo Clusieae); endosperma nuclear, evanescente; embrião grande hipocotilar, com cotilédones minúsculos (tribos
Clusieae, Garcinieae e Moronobeae).

Entre os gêneros da família Clusiaceae descritos por CORNER (1976), sete apresentam embrião hipocotilar: Allanblackia, Clusia, Garcinia, Havetiopsis, Pentadesma, Septogarcinia e Tovomitopsis. Segundo Barroso (1978), o embrião "hipocotilar", caracteriza-se pelo desenvolvimento acentuado do eixo hipocótilo-radícula, que passa a assumir totalmente a função de armazenamento de reservas, sendo os cotilédones vestigiais. Nessa categoria essa autora incluiu os embriões de Rheedia, Tovomita, Symphonia e também o de Platonia.

Entretanto, o embrião de $P$. insignis enquadra-se mais apropriadamente no tipo "conferruminado" (BARROSO, 1978), já que é formado apenas pelo longo e espesso eixo hipocotilo-radícula.

Na classificação de PLANCHON \& TRIANA apud BRANDZA (1908), BRANDZA (1908) e GUILLAUMIN (1910) o embrião de $P$. insignis enquadrase no tipo II que caracteriza as tribos Moronobeae e Garcinieae, onde o eixo hipocótilo-radícula é "tuberoso" e os cotilédones extremamente reduzidos.

A subdivisão das Guttiferae (Clusiaceae) em cinco subfamílias foi baseada entre outras, nas características dos frutos e sementes. Na subfamília Moronoboideae, dentro da qual se encontra $P$. insignis, as sementes não possuem arilo e o embrião é "indiferenciado" (HEYWOOD, 1985).

MAURY-LECHON et al. (1980) descreveram o embrião de Symphonia globulifera como desprovido de cotilédones. ROUSTEAU (1986) afirmou 
que, nessa espécie, as reservas estão armazenadas no "hipocótilo hipertrofiado", tendo incluido o embrião no tipo correspondente àqueles que apresentam cotilédones hipógeos, suculentos.

Ainda com relação às sementes de $P$. insignis, análises químicas foram realizadas por PESCE (1934) e por PECHNIK \& CHAVES (1945). Ambos deram destaque à ocorrência de gordura na semente desta espécie, aspecto este que também foi verificado no presente estudo.

BRANDZA (1908) chamou a atenção para o fato de que nas Clusiaceae o embrião é muito rico em substâncias oleoresinosas. Em Allanblackia floribunda os lipídios, que constituem o principal material de reserva, acumulam-se em todas as células do embrião (DELAY \& MANGENOT, 1960). BASTA \& BASTA (1984) afirmaram que, em Kielmeyera coriacea as substâncias de reserva estão contidas nos cotilédones sob a forma de gotículas de óleo.

\section{Bibliografia citada}

ALVES, S.; JENNINGS, W.G. 1979. Volatile composition of certain Amazonian fruits. Food Chemistry, 4: 149-59.

BARROSO, G.M. 1978. Curso sobre identificação de sementes. Pelotas: CETREISUL (Mimeogr.).

BASTA, S. B. D,; BASTA, F. 1984. Estudos morfológicos das sementes e do desenvolvimento das plântulas de Kielmeyera coriacea Mart. Brasil Florestal, 58: $25-30$.

BERG, M.E. van den. 1982. Plantas medicinais na Amazônia: contribuição ao seu estudo sistemático. Belém: CNPq/PTU. 223 p.

BRANDZA, G. 1908. Recherches anatomiques sur la germination des Hypéricacées et des
Guttiferes. Annales des Science Naturelles Bot., série 9, 8: 221-300.

CALZAVARA, B.B.G. 1970. Fruteiras: abieiro, abricozeiro, bacurizeiro, biribazeiro, cupuaçuzeiro. Série Culturas da Amazônia, Belém, 1(2): 46-84.

CAMPOS, F.A.M., PECHNIK, E.; SIQUEIRA, R. de. - 1951. Valor nutritivo de frutas brasileiras. Trabalhos e Pesquisas, (4): 61-171.

CAVALCANTE, P.B. 1976. Frutos comestíveis da Amazônia. 2. ed. Belém: Falangola. 154 p.

CORNER, E.J.H. - 1976. The seeds of dicotyledons. Cambridge: University Press. $2 \mathrm{v}$.

DELAY, C.; MANGENOT, G. 1960. Le développement de la graine chez Allanblackia floribunda Oliv. Annales des Sciences Naturelles Bot., série 12, 1: 387-439.

ENGLER, A. 1888. Gutiferae. In: MARTIUS, C.F.P. von Flora Brasiliensis, 12(3): 381-486.

FONT QUER, P, 1985. Diccionario de Botánica. Barcelona: Editorial Labor. 1244 p.

GUILLAUMIN, A. 1910. L'etude des germinations appliquée à la classification des genres et a la phylogénie des groupes. Revue Générale de Botanique, 22: 449-468.

HEYWOOD, V.H. (ed.). 1985. Flowering plants of the world. London, Sydney: Croom Helm. $336 \mathrm{p}$.

MANIERI, C.; LOUREIRO, A.A. 1964, Madeiras de Symphonia globulifera L., $P$. insignis Mart., Moronobea coccinea Aubl. e Moronobea pulchra Ducke (Guttiferae). Estudo anatômico macro e microscópico, como contribuição para a sua identificação. Botânica, Manaus, 18: 28 p.

MAURY-LECHON, G., CORBINEAU, E.; CÔME, D. 1980. Données préliminaires sur la germination des graines et la conservation des plantules de Symphonia globulifera L.f. (Guttifere). Revue Bois et Forêts des Tropiques, (193): 35-40.

METCALFE, C.R.; CHALK, L. 1983. Anatomy of the dicotyledons. Oxford: Clarendon Press. v. 2.

MOURÃO, K.S.M.; BELTRATI, C.M. 1995. 
Morfologia dos frutos, sementes e plântulas de Platonia. insignis Mart. (Clusiaceae). 1. Aspectos anatômicos dos frutos e sementes em desenvolvimento. Acta Amazonica, 25 (1/2): 11-32

NAZARÉ, R.F.R. de; MELO, C.F.M. de. 1981. Extração do aroma de bacuri e sua utilização como flavorizante em iogurte natural. Circular Técnica, Belém, EMBRAPA/CPATU, 15: $13 \mathrm{p}$.

OLIVEIRA, D.M.T. de. 1991. Morfologia e desenvolvimento dos frutos, sementes $e$ plântulas de Inga fagifolia Willd e $I$. urüguensis Hook et Arn (Fabaceae, Mimosoideae) Rio Claro: UNESP, 1991. 181 p. Dissertação (Mestrado em Biologia Vegetal) - Instituto de Biociências, Universidade Estadual Paulista.

PAULA, R.D, de G. 1945. Estudo químico do mesocarpo de bacuri. Anais da Associação Química do Brasil, Rio de Janeiro, 4(3): 173-176.

PECHNIK, E.; CHAVES, J.M. 1945. Chemical study of the fatty substance of the bacury (P. insignis Mart.). Revista de Química Industrial, 14(163): 418-419.

PECHNIK, E.; GUIMARĀES, L.R.; CHAVES, J.M. 1962. Simpósio sobre alimentos da Amazônia. Trabalhos e Pesquisas do Instituto de Nutrição, 6: 121-31.

PESCE, C. 1934. Sementes oleaginosas da Amazônia, O Campo, 4(7): 2-46.
PIO CORRÊA, M. 1926. Dicionário das plantas úteis do Brasil e das exóticas cultivadas. Rio de Janeiro: Ministério da Agricultura. v. 1.

RADFORD, A.E.; DICKISON, W.C.; MASSEY, J.R.; BELL, C.R. 1974. Vascular Plant Systematics. New york: Herper \& Row Publ. 891 p

ROOSMALEN, M.G.M. van. 1985a. Fruits of the Guianan Flora. Netherlands: Institute of Systematic Botany, Fruits of the Guianan Flora Utrecht. University, Silvicultural Department of Wageningen, Agricultural University, $463 \mathrm{p}$.

-. 1985 b. Habitats preferences, diet, feeding strategy and social organization of the black spider monkey (Ateles paniscus paniscius Linnaeus 1758) in Surinam. Acta Amazônica, 15 (3/4): 238 p.

ROTH, I. 1977. Fruits of Angiosperms. Berlin: Borntraeger. 675 p. (Handbuch der Pflanzenanatomie).

ROUSTEAU, A, 1986. Les plantules d'arbres forestiers de Guadeloupe: adaptations structurales et dimensionnelles. Mémoires du Muséum National d'Histoire Naturelle Serie A, Zoologie, 132: 185-191.

VESTAL, P.A. 1937. The significance of comparative anatomy in stablishing the relationship of the Hypericaceae to the Guttiferae and their allies. Phillippine Journal of Science, 64(3): 199-256. 